\title{
Analisis Strategi Pengembangan Bisnis Melalui Matriks SWOT pada Startup MakananHalal.id
}

\author{
Ratih Puspita Sari* \\ Program Studi Administrasi Bisnis Terapan, Politeknik Negeri Jakarta \\ Jalan Prof. Dr. G.A. Siwabessy, Kampus Universitas Indonesia, Depok, Indonesia \\ ratihpuspitaas@gmail.com
}

\section{Iis Mariam}

Program Studi Administrasi Bisnis Terapan, Politeknik Negeri Jakarta

Jalan Prof. Dr. G.A. Siwabessy, Kampus Universitas Indonesia, Depok, Indonesia

iis.mariam@bisnis.pnj.ac.id

\section{Mawarta Onida Sinaga}

Program Studi Administrasi Bisnis Terapan, Politeknik Negeri Jakarta

Jalan Prof. Dr. G.A. Siwabessy, Kampus Universitas Indonesia, Depok, Indonesia mawarta.onida@bisnis.pnj.ac.id

Diterima: 28-08-2020 | Disetujui: 07-07-2021 | Dipublikasi: 31-07-2021

\begin{abstract}
ABSTRAK
Tujuan penelitian ini adalah untuk untuk mendapatkan alternatif strategi yang digunakan oleh startup MakananHalal.id dalam mengembangkan bisnisnya. Penelitian ini bertujuan mengidentifikasi masalah tentang analisis faktor internal, faktor eksternal dan matriks SWOT dalam menciptakan strategi pengembangan bisnis. Metodologi yang digunakan kualitatif deskriptif dan menggunakan wawancara mendalam. Informan penelitian yaitu CEO dan karyawan MakananHalal.id serta pemilik restaurant yang bekerjasama dengan MakananHalal.id. Hasil penelitian untuk pengembangan bisnis pada startup MakananHalal.id dikelompokkan pada 4 kategori yaitu: (1) Alternatif Strategi SO memperluas jaringan makanan halal di seluruh area DKI Jakarta menggunakan media sosial untuk mempromosikan MakananHalal.id dan bergabung menjadi mitra driver. (2) Alternatif Strategi WO dengan membuat akun media sosial dengan konten menarik untuk meningkatkan traffic. mengadakan live quiz atau giveaway di media sosial selama sistem off, dan memperluas jangkauan wilayah dan jarak pengiriman agar minimal area DKI Jakarta bisa mengakses MakananHalal.id. (3) Alternatif Strategi ST dengan melakukan kerjasama para pebisnis jastip agar melakukan pre-order di aplikasi MakananHalal.id. mengadakan promosi dan marketing bahwa MakananHalal.id lebih fleksibel dibanding aplikasi lain, dan (4) alternatif Strategi WT: menjalin kerjasama dengan pelaku usaha restoran yang belum membuka online delivery, meningkatkan jangkauan jarak pengiriman lebih dari $25 \mathrm{~km}$ sebagai improvement untuk bersaing dengan aplikasi pesaing. Penelitian selanjutnya fokus pada strategi pemasaran digital usaha makanan halal.
\end{abstract}

Kata Kunci:

Alternatif Strategi; Pengembangan Bisnis; SWOT

*Corresponding author 


\section{ABSTRACT}

The purpose of this study was to find alternative strategies used by FoodHalal.id startups in developing their business. The problems regarding the analysis of internal factors, external factors, and SWOT matrix. The methodology used is descriptive qualitative with in-depth interviews, informants are CEOs and employees of MakanHalal.id, restaurant owners who collaborate with MakanHalal.id. The results of research are grouped into 4 categories, namely: (1). Alternative SO Strategy expands the halal food network in all areas of DKI Jakarta using social media to promote Halal Food, join as driver partners. (2) Alternative WO strategy by creating social media accounts with interesting content to increase traffic. holding live quizzes or giveaways on social media while the system is off, expanding the coverage area and delivery distance in DKI Jakarta area can access Halal.id Food, (3) Alternative ST Strategy by collaborating with businessmen to pre-order on the FoodHalal.id application, holding promotions, marketing that Halal.id is more flexible than other applications, (4) Alternative WT strategy: establishing cooperation with restaurant businesses that have not yet opened their own online delivery, increasing the delivery distance of more than $25 \mathrm{~km}$ to be able to compete with competing applications. Further research focus on digital marketing strategies for halal food businesses.

Keywords:

Alternative Strategy; Developing Business; SWOT 


\section{PENDAHULUAN}

Perkembangan bisnis di zaman sekarang semakin mengarah pada industri 4.0 dan lebih memanfaatkan teknologi sebagai media bisnis tersebut. Banyak bisnis yang bermula dari inovasi kecil dan kreatif untuk menjawab berbagai kebutuhan masyarakat yang semakin lama semakin beragam kebutuhannya. Inovasi tersebut memberikan banyak kemudahan bagi masyarakat dalam melakukan aktivitas sehari-hari. Di zaman modern ini bisnis yang dimulai dari ide kecil untuk mencari solusi dari permasalahan masyarakat disebut startup. Startup merupakan kata serapan dari bahasa Inggris yang berarti memulai sesuatu. Perkembangan startup di Indonesia sendiri sangat meningkat dari tahun ke tahun. Data Sensus Ekonomi pada tahun 2016 lalu yang didapat dari Badan Pusat Statistik menyatakan dalam sepuluh tahun terakhir industri e-commerce yang didalamnya ada beberapa berbentuk startup di Indonesia tumbuh sekitar 17\% dengan total unit usahanya mencapai 26,2 juta.

Untuk mengembangkan startup dapat ditempuh dengan berbagai strategi yang digunakan dalam bisnis, termasuk bagaimana manajemen strateginya. Manajemen strategi adalah seni dan pengetahuan dalam merumuskan, mengimplementasikan, serta mengevaluasi keputusan-keputusan lintas fungsional yang memungkinkan sebuah organisasi untuk mencapai tujuan (David, 2011; Muhammad, 2013). Dalam mengembangkan usaha, strategi yang dilakukan pun beragam. Salah satunya menggunakan metode matriks SWOT. Matriks SWOT dapat menggambarkan secara jelas bagaimana peluang dan ancaman eksternal yang dihadapi perusahaan dapat disesuaikan dengan kekuatan dan kelemahan yang dimilikinya (David, 2011; Quincy, 2012). Merujuk pada Muhammad (2013) bahwa analisis SWOT dengan TOWS dapat digunakan sebagai salah satu alat analisis yang paling sering digunakan dalam membantu bagaimana cara merancang suatu bangunan strategi. Seiring perkembangan zaman, manusia lebih memilih cara praktis dalam mendapatkan makanan yang diinginkan. Sekarang sudah ada beberapa startup pengantaran makanan yang bisa dipesan melalui smartphone. Hal ini praktis dilakukan bagi sebagian orang yang tidak mempunyai banyak waktu sehingga bisa mengerjakan pekerjaan lain di waktu menunggu makanan datang. Beberapa contoh startup yang melayani pengantaran makanan di Indonesia adalah gofood, grabfood dan salah satu startup yang baru saja muncul adalah MakananHalal.id.

MakananHalal.id merupakan perusahaan aplikasi teknologi yang mulai dibangun pada tahun 2017. Aplikasi ini berbasis web dan mobile yang memberikan kemudahan akses bagi pengguna jasa dalam memesan makanan dan minuman halal di jaringan restoran halal di Indonesia. MakananHalal.id bermitra dengan para pengemudi ojek guna menyediakan layanan terpercaya dengan harga pasti. Sejak mulai dibangun hingga bulan Maret tahun 2020, sudah ada 181 merchant yang bergabung bersama MakananHalal.id. MakananHalal.id menggunakan website yaitu MakananHalal.id, aplikasi di Play store dan juga App store. MakananHalal.id memiliki keunggulan tersendiri dibanding dengan aplikasi jasa pengantaran makanan lain yaitu hanya menawarkan restoran-restoran yang $100 \%$ diyakini halal. Dalam beberapa tahun terakhir, bisnis jasa layanan pengantaran makanan yang paling populer di masyarakat adalah layanan pengantaran makanan dari 
GoJek yaitu GoFood dan layanan pengantaran makanan dari Grab yaitu GrabFood. Dengan adanya startup MakananHalal.id, maka menambah daftar bisnis jasa layanan pengantaran makanan berbasis online di Indonesia. Untuk menghadapi persaingan bisnis dan menjadi startup layanan jasa pengantaran makanan yang bisa dikenal banyak masyarakat, dibutuhkan strategi agar startup MakananHalal.id ini berkembang dan diminati masyarakat. Bisnis layanan pengantaran makanan sudah banyak namun baru MakananHalal.id yang menyediakan dan menjamin makanan yang dipesan oleh pelanggan diyakini $100 \%$ halal. Hal ini bisa menjadi kekuatan untuk menghadapi persaingan dan mengembangkan bisnis startup MakananHalal.id ini. Berdasarkan uraian latar belakang di atas, maka masalah yang muncul adalah bagaimana analisis SWOT yang digunakan untuk menciptakan strategi pengembangan bisnis pada startup MakananHalal.id. Tujuan dari penelitian ini adalah untuk menghasilkan alternatif strategi yang sesuai dengan keadaan startup MakananHalal.id berdasarkan dari hasil perhitungan faktor kelemahan dan kelebihan yang dimiliki oleh startup MakananHalal.id. Manfaat yang dapat diperoleh dari hasil penelitian ini adalah dapat memberikan alternatif strategi untuk pemilik startup MakananHalal.id dalam mengembangkan usahanya. Oleh karena itu penelitian ini fokus pada analisis strategi pengembangan bisnis di startup MakananHalal.id menggunakan SWOT.

Dalam manajemen strategi juga dipahami bahwa manajemen strategi merupakan seni dan pengetahuan di dalam merumuskan, mengimplementasikan serta mengevaluasi sesuai dengan visi, misi dan tujuan dari organisasi (David, 2011) Dalam pengembangan usaha juga perlu dipertimbangkan cara memperbaiki bagaimana pelaksanaan pekerjaan yang saat ini dan yang akan datang dilakukan sehingga informasi yang diperoleh akan mempengaruhi sikap untuk usaha menjadi lebih produktif. Kondisi ini sesuai dengan tahapan dalam pengembangan usaha melalui kepemilikan ide usaha, penyaringan ide atau konsep usaha, pengembangan rencana usaha, implementasi rencana dan pengendalian usaha. Manajemen strategi dalam pengembangan usaha menjadi penting, terutama dalam menentukan analisis strategi yang tepat dan benar-benar sesuai dengan jenis usaha yang dilaksanakan (Antoko et al., 2018; Hamim \& Larso, 2016; Simon, 2018). Adapun salah satu strategi yang digunakan adalah SWOT yang menjelaskan bagaimana kekuatan, kelemahan, kesempatan serta ancaman yang terjadi dalam bisnis membutuhkan strategi yang tepat dan memberikan solusi yang sesuai dengan masalah terutama dalam konteks bisnis MakananHalal.id yang saat ini sedang tumbuh dan berkembang sebagai startup bisnis di masyakarat. (David, 2011; Muhammad, 2013; Quincy, 2012; Rangkuti, 2011)

\section{METODE RISET}

Penelitian ini menggunakan jenis penelitian kualitatif deskriptif. Menurut Anggito dan Setiawan (2018); Manzilati (2017) Penelitian kualitatif bersifat deskriptif, langkah ini penelitian harus mendeskripsikan suatu objek, fenomena atau setting sosial yang akan dituangkan dalam tulisan yang bersifat naratif. Jadi penelitian bersifat deskriptif ditujukan untuk menggambarkan fenomena yang 
ada tanpa ada manipulasi, sehingga akan menggambarkan suatu kondisi secara apa adanya dan dituangkan dalam tulisan yang bersifat naratif. Teknik pengumpulan data yang digunakan dalam penelitian ini adalah (a) observasi non partisipan dimana dalam peneliti tidak terlibat dengan subjek yang diamati pada pelaku bisnis startup makanan halal, tetapi hanya berperan sebagai pengamat independen saja. Penulis memilih observasi non partisipan agar tidak ada keberpihakan dan dapat lebih detail melihat kelemahan serta ancaman yang akan digunakan dalam analisis SWOT, dan independen tidak dipengaruhi oleh pihak manapun, (b) wawancara mendalam dipilih penulis dengan tujuan agar mendapatkan informasi secara intens dan jelas, serta informan bisa lebih leluasa dalam menyampaikan informasi. Wawancara akan dilakukan dengan beberapa informan, diantaranya: CEO startup MakananHalal.id, Staf Administrasi startup MakananHalal.id, Koordinator bagian Merchant \& Driver startup MakananHalal.id, serta pemilik resto yang bekerja sama dengan MakananHalal.id dan aplikasi pesaing. Adapun yang menjadi informan dalam penelitian ini adalah CEO dan karyawan startup MakananHalal.id, serta pemilik restoran yang bekerjasama dengan startup MakananHalal.id.

Teknik analisis data dari model analisis interaktif Miles \& Huberman dalam Sugiyono (2018) menjelaskan tentang reduksi data: Dalam proses reduksi data ini, penulis melakukan sortir dari datadata yang telah terkumpul mengenai bisnis startup pada MakananHala.id selanjutnya data tersebut diseleksi lagi mana data yang akan berguna untuk mendukung penelitian dan mana yang tidak terutama dalam manajemen strategi yang berhubungan dengan visi dan misi dari bisnis MakananHalal.id. Dalam sajian data yang penulis akan lakukan adalah dengan alat ukur matriks IFAS dan EFAS sesuai dengan rujukan. Selanjutnya setelah data dikelompokkan ke dalam matriks IFAS dan EFAS, penulis akan melakukan analisis SWOT sehingga menghasilkan data tentang indikator yang menjadi kelemahan, kelebihan, peluang dan ancaman di startup MakananHalal.id untuk kemudian dilakukan analisis strategi yang harus dipilih untuk mengembangkan bisnis startup MakananHalal.id ini. Penarikan kesimpulan/Verifikasi dari penelitian dilakukan setelah semua langkah-langkah penelitian telah dipenuhi. Hasil simpulan yang diharapkan berupa alternatif strategi yang bisa dilakukan oleh startup MakananHalal.id untuk mengembangkan usahanya. Penulis menggunakan matriks SWOT sebagai salah satu teknik analisis data dengan pertimbangan bahwa matriks SWOT memiliki empat tipe strategi pengembangan usaha, yaitu: (a) strategi SO adalah strategi yang disusun dengan cara menggunakan semua kekuatan untuk merebut peluang, (b) strategi WO adalah strategi yang disusun dengan cara meminimalkan kelemahan untuk memanfaatkan peluang yang ada, (c) strategi ST adalah strategi yang disusun dengan cara menggunakan semua kekuatan untuk mengatasi ancaman, dan (d) strategi WT adalah strategi yang disusun dengan cara meminimalkan kelemahan untuk menghindari ancaman (David, 2011; Muhammad, 2013)

\section{HASIL PENELITIAN DAN PEMBAHASAN}

Dalam penelitian ini teknik pengumpulan data dilakukan yaitu wawancara mendalam dengan 4 orang informan yaitu Lukman Salim selaku CEO Startup MakananHalal.id, Ahmad Yani selaku 
Merchant \& Driver Coordinator dari MakananHalal.id, Ayu Rahmawati selaku Staf Administrasi dan Mahmud selaku Marketing Representative terkait dengan faktor-faktor internal (IFAS/Internal Factor Analysis Strategy) dan EFAS (External Factor Analysis Strategy). Indikator yang digunakan dalam wawancara untuk IFAS dan EFAS merujuk pada teori David (2011); Muhammad (2013); Wheelen \& Hunger (2010) untuk konsep TOWS. Kekuatan IFAS merujuk pada faktor: (a) sumber daya, (b) kebijakan perusahaan, (c) keuangan, (d) strategi dan budaya perusahaan. Sedangkan faktor EFAS merujuk pada: (a) kekuatan ekonomi, (b) kekuatan sosial budaya, demografis dan lingkungan, (c) kekuatan politik, pemerintahan, dan hukum, (d) kekuatan teknologi, dan (e) kekuatan kompetitif. Hasil rekapitulasinya bisa dilihat sebagai berikut:

Tabel 1. Rekapitulasi Perhitungan Faktor Internal Startup MakananHalal.id

\begin{tabular}{|c|c|c|c|c|c|c|c|c|}
\hline No & Kekuatan & Bobot & Rating & Score & Kelemahan & Bobot & Rating & Score \\
\hline 1. & $\begin{array}{l}\text { Makanan yang } \\
\text { tersedia di aplikasi } \\
\text { MakananHalal.id } \\
\text { diyakini } 100 \% \text { Halal. }\end{array}$ & 0.129 & 4 & 0.516 & $\begin{array}{l}\text { Jangkauan wilayah } \\
\text { aplikasi MakananHalal.id } \\
\text { baru berada di kawasan } \\
\text { Jakarta Timur, Jakarta } \\
\text { Barat dan Jakarta Utara. }\end{array}$ & 0.103 & 2 & 0.206 \\
\hline 2. & $\begin{array}{l}\text { Ada sistem pre-order } \\
\text { di aplikasi } \\
\text { MakananHalal.id } \\
\text { untuk memudahkan } \\
\text { konsumen. }\end{array}$ & 0.078 & 3 & 0.234 & $\begin{array}{l}\text { Kurangnya strategi } \\
\text { marketing dari } \\
\text { MakananHalal.id } \\
\text { membuat pengguna } \\
\text { aplikasi masih sedikit. }\end{array}$ & 0.043 & 2 & 0.086 \\
\hline 3. & $\begin{array}{l}\text { Penggunaan box } \\
\text { khusus delivery ke } \\
\text { konsumen. }\end{array}$ & 0.121 & 4 & 0.484 & $\begin{array}{l}\text { Jarak pengiriman yang } \\
\text { terbatas hanya sampai } 25 \\
\mathrm{~km} \text {. }\end{array}$ & 0.129 & 1 & 0.129 \\
\hline 4. & $\begin{array}{l}\text { Metode pembayaran } \\
\text { di aplikasi } \\
\text { MakananHalal.id } \\
\text { sangat beragam. }\end{array}$ & 0.129 & 4 & 0.516 & $\begin{array}{l}\text { Sistem di aplikasi } \\
\text { MakananHalal.id masih } \\
\text { sering on-off. }\end{array}$ & 0.121 & 2 & 0.242 \\
\hline 5. & $\begin{array}{l}\text { Konsumen bisa } \\
\text { flexible memesan di } \\
\text { aplikasi mobile } \\
\text { maupun website. }\end{array}$ & 0.069 & 4 & 0.276 & & & & \\
\hline 6. & $\begin{array}{l}\text { Mudah untuk menjadi } \\
\text { mitra driver. }\end{array}$ & 0.078 & 4 & 0.312 & & & & \\
\hline
\end{tabular}

Sumber: Hasil Olah Data Penulis

Tabel 2. Rekapitulasi Perhitungan Faktor Eksternal Startup MakananHalal.id

\begin{tabular}{|c|c|c|c|c|c|c|c|c|}
\hline No. & Peluang & Bobot & Rating & Score & Ancaman & Bobot & Rating & Score \\
\hline 1. & $\begin{array}{l}\text { Makanan masih } \\
\text { menjadi kebutuhan } \\
\text { utama masyarakat. }\end{array}$ & 0.145 & 3 & 0.435 & $\begin{array}{lr}\text { Restoran } & \text { membuka } \\
\text { online } & \text { delivery } \\
\text { sendiri. } & \end{array}$ & 0.184 & 1 & 0.184 \\
\hline 2. & $\begin{array}{l}\text { Banyaknya restoran di } \\
\text { DKI Jakarta yang } \\
\text { belum bekerjasama. }\end{array}$ & 0.184 & 4 & 0.736 & $\begin{array}{ll}\text { Aplikasi } & \text { pesaing } \\
\text { lebih } & \text { dikenal } \\
\text { masyarakat. } & \end{array}$ & 0.211 & 1 & 0.211 \\
\hline 3. & $\begin{array}{l}\text { Perkembangan media } \\
\text { sosial sebagai sarana } \\
\text { marketing. }\end{array}$ & 0.171 & 4 & 0.684 & $\begin{array}{l}\text { Maraknya usaha jasa } \\
\text { titip sebagai pesaing } \\
\text { baru. }\end{array}$ & 0.105 & 2 & 0.210 \\
\hline
\end{tabular}

Sumber: Hasil Olah Data Penulis

Startup MakananHalal.id memiliki 6 faktor kekuatan dan 4 faktor kelemahan yang dapat digunakan sebagai indikator dalam menentukan formulasi strategi SWOT. Faktor kekuatan tertinggi adalah makanan yang tersedia di aplikasi MakananHalal.id diyakini 100\% Halal dan metode 
pembayaran di aplikasi MakananHalal.id sangat beragam dengan skor sama yaitu 0.129. Sedangkan untuk faktor kelemahan yang paling lemah adalah kurangnya strategi marketing dari MakananHalal.id membuat pengguna aplikasi masih sedikit. Hasil ini sejalan dengan teori yang disampaikan oleh David (2011); Quincy (2012); Rangkuti (2011); Wheelen \& Hunger (2010) untuk konsep TOWS pada Startup MakananHalal.id yang memiliki 3 faktor peluang dan 3 faktor ancaman yang digunakan sebagai indikator dalam analisis SWOT. Merujuk pada matriks External Factor Analysis Strategy (EFAS) di atas menyatakan bahwa peluang paling berpengaruh terhadap strategi pegembangan bisnis startup MakananHalal.id adalah banyaknya restoran di DKI Jakarta yang belum bekerjasama. Sedangkan untuk ancaman yang paling berpengaruh adalah aplikasi pesaing yang lebih dikenal oleh masyarakat. Berdasarkan rekapitulasi perhitungan Internal Factor Analysis Strategy (IFAS) dan External Factor Analysis Strategy (EFAS) maka selanjutnya dilakukan perhitungan dengan matriks SWOT sebagai berikut:

Tabel 3. Matriks SWOT

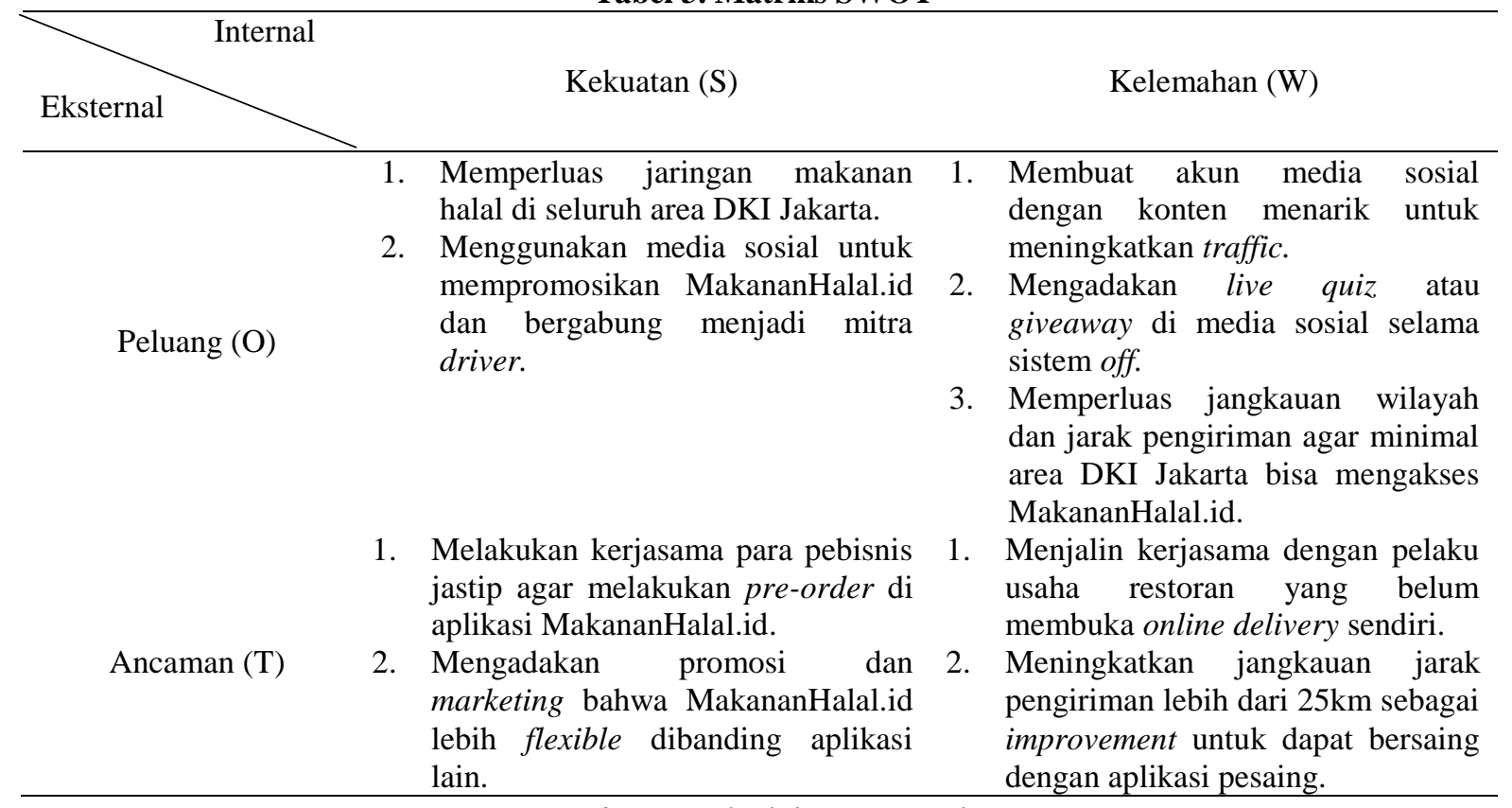

Sumber: Hasil Olah Data Penulis

Berdasarkan matriks SWOT yang telah dilakukan, menghasilkan beberapa alternatif strategi yaitu strategi SO, WO, ST dan WT yang dapat diadopsi untuk diterapkan oleh MakananHalal.id dalam merumuskan strategi dan mengembangkan bisnisnya pada saat ini dan yang akan datang. Lebih lanjut dapat dikembangkan pada hasil penelitian ini bahwa pemanfaatan teknologi dalam bidang pangan saat ini telah berkembang pesat dengan hadirnya aplikasi teknologi terutama untuk proses menyeleksi bahan makanan yang dapat diawetkan serta diolah untuk dapat dikemas dengan proses teknologi yang lebih baik lagi sehingga dapat dengan aman dikonsumsi oleh pelanggan dan konsumen. Proses teknologi lain yang juga berdampak pada pendistribusian produk makanan halal adalah strategi pemasaran yang berbasis digital yang diadopsi sebagai salah satu keunggulan dari bisnis startup saat ini untuk dapat menjangkau konsumen dan pelanggan lebih cepat dan menarik. 
Proses kemasan produk makanan juga perlu diperhatikan lagi karena selera dan kebutuhan konsumen variatif serta harus lebih menarik dan hal ini ada kesamaan di dalam penelitian terdahulu (Antoko et al., 2018; Hamim \& Larso, 2016; Simon, 2018). Hasil penelitian ini masih memiliki keterbatasan dimana fokus pada penerapan indikator yang diteliti pada IFAS dan EFAS, alternatif lain dalam analisis dapat dikembangkan tidak hanya SWOT tetapi juga TOWS untuk bisnis makanan halal (Rangkuti, 2011; Wheelen \& Hunger, 2010)

\section{KESIMPULAN DAN SARAN}

\section{Kesimpulan}

Berdasarkan hasil penelitian, maka kesimpulan dalam penelitian ini adalah:

1. Startup MakananHalal.id melakukan pengembangan bisnis nya dengan cara memilih alternatif strategi yang sudah dihasilkan yaitu memperluas jaringan makanan halal di seluruh area DKI Jakarta dimana kebutuhan konsumen untuk makan halal cenderung bertambah.

2. Untuk mempromosikan produk MakananHalal.id digunakan media sosial serta perusahaan startup bergabung menjadi mitra driver, membuat akun media sosial dengan konten menarik tentang produk yang ditawarkan sehingga dapat meningkatkan traffic, mengadakan live quiz atau giveaway di media sosial selama sistem off, serta memperluas jangkauan wilayah dan jarak pengiriman di wilayah DKI Jakarta sehingga dapat mengakses MakananHalal.id.

3. Langkah lainnya adalah melakukan kerjasama para pebisnis jastip agar melakukan pre-order di aplikasi MakananHalal.id, mengadakan promosi dan memanfaatkan digital marketing untuk MakananHalal.id yang lebih fleksibel dibanding aplikasi lain. Sedangkan alternatif strategi lainnya dengan menjalin kerjasama dengan pelaku usaha restoran yang belum membuka online delivery sendiri.

4. Salah satu faktor dalam EFAS mengenai demografi maka penelitian ini juga fokus pada jarak pengiriman produk lebih dari $25 \mathrm{~km}$ sebagai upaya untuk meningkatkan daya saing produk makanan halal serta pemanfaatan aplikasi teknologi informasi yang lebih mudah untuk melengkapi kekuatan bisnis untuk dapat bersaing dengan pesaing lainnya sesuai dengan hasil penelitian terdahulu mengenai analisis strategi bisnis.

\section{Saran}

Saran yang dapat peneliti berikan berdasarkan hasil penelitian adalah:

1. Startup MakananHalal.id perlu memperluas jaringan makanan halal dan bekerjasama dengan restoran dan kedai minimal di seluruh area DKI Jakarta agar mampu mengembangkan bisnisnya. MakananHalal.id perlu strategi seperti digital marketing melalui media sosial untuk meningkatkan promosi dan memberikan awareness kepada masyarakat agar lebih mudah dalam pemesanan produk. 
Sari, R.P., Mariam, I., \& Sinaga, M.O. (2021). Analisis Strategi Pengembangan Bisnis ....

2. MakananHalal.id perlu meningkatkan pemakaian akses dari sistem yang ada dalam aplikasi pemesanan produk secara lebih variatif, atraktif, menarik dan inovatif sehingga konsumen dan pelanggan menjadi lebih tertarik untuk memesan serta membeli produk secara daring dibandingkan dengan promosi produk makanan lainnya.

3. Penelitian selanjutnya harus lebih fokus pada analisis strategi yang mampu memberikan hasil lebih baik untuk IFAS dan EFAS sehingga bisnis makanan halal dapat menjangkau pasar lebih luas lagi tidak hanya di DKI Jakarta dan mampu memenangkan persaingan. 


\section{DAFTAR PUSTAKA}

Anggito, A. (2018). Metode Penelitian Kualitatif. CV. Jejak.

Antoko, Si. T., Fathoni, A., \& Minarsih, M. M. (2018). Perumusan Strategi Pemasaran Berdasarkan Analysis SWOT: Studi Kasus Pada PT. Aquafaram Nusantara Semarang. Journal of Management, 4(4).

David, F. R. (2011). Strategic Management Manajemen Strategi Konsep (Ed. ke-12). Salemba Empat.

Hamim, M. G. P., \& Larso, D. (2016). Business Development Strategy Of Culinary Strart-Up: A Case Study of Kedai Mas Gibo. The Journal of Innovation and Enterpremerurship, 1(1), 29-42.

Manzilati, A. (2017). Metodologi Penelitian Kualitatif: Paradigma, Metode dan Aplikasi. Universitas Brawijaya Press (UB Press).

Muhammad, S. (2013). Manajemen Strategik Konsep dan Alat Analisis (Edisi Keli). UPP STIM YKPN. Yogyakarta.

Quincy, R. (2012). SWOT Analysis Raising Capacity of your Organization. Huamin Research Center.

Rangkuti, F. (2011). SWOT Balanced Scorecard; Teknik Menyusun Strategi Korporat yang Efektif Plus Cara Mengelola Kinerja dan Resiko. PT. Grameda Jakarta.

Simon, J. (2018). When Food is Comfort. New World Library.

Sugiyono. (2018). Metode Peneiltian Kuantitatif, Kualitatif dan R\&D. In Alfabeta Bandung.

Wheelen, T. L., \& Hunger, J. D. (2010). Strategic Management and Business Policy: Achieving Sustainability (12th Editi). Pearson Education. 